\title{
Plasminogen activator inhibitor: a risk factor for myocardial infarction in diabetic patients
}

\author{
Rosaire P Gray, John S Yudkin, David L Patterson
}

\begin{abstract}
Objective-To determine whether diabetic patients admitted with acute myocardial infarction have impaired fibrinolytic activity due to raised plasminogen activator inhibitor compared with non-diabetic patients.
\end{abstract}

Setting-A district general hospital.

Patients-90 non-diabetic and 38 diabetic patients admitted with acute myocardial infarction.

Results-Both plasminogen activator inhibitor activity and antigen were significantly higher in diabetic than in nondiabetic patients $(24.7(6.8) v 18.5(6.8)$ AU/ml; $p=0.0001$ and $64 \cdot 2$ (range $13 \cdot 1$ to 328.8 ) $v 38.5$ (range 10.9 to $173.7 \mathrm{ng} / \mathrm{ml}$; $=3.3 ; \mathbf{p}=0.0008$ ) with a positive correlation between activity and antigen $\left(r_{\mathrm{s}}=\right.$ $0.51 ; \mathbf{p}=0.0001)$. In both groups, activity and antigen concentrations were significantly higher than in diabetic and nondiabetic subjects without coronary artery disease $(p=0.002$ to 0.0001 for each comparison). Plasminogen activator inhibitor activity correlated significantly with admission plasma glucose $(r=0.32$; $\mathbf{p}=0.0001)$, glycated haemoglobin $(r=$ $0.32 ; \quad p=0.0001)$, admission plasma insulin $\left(r_{s}=0.48 ; p=0.001\right)$, and Killip grade of heart failure both on admission $\left(r_{\mathrm{s}}=0.27 ; \mathrm{p}=0.001\right)$ and on discharge $\left(r_{\mathrm{s}}\right.$ $=0.22 ; \mathrm{p}=0.006$ ), but not with cumulative creatine kinase $M B$ isoenzyme release $\left(r_{\mathrm{s}}=-0.08\right)$. There were similar but weaker correlations between tissue plasminogen activator antigen and admission plasma glucose, glycated haemoglobin, and insulin. In 18 patients (12 non-diabetic and six diabetic) plasminogen activator inhibitor activity was measured between six and 12 months $(8 \cdot 3$ (1.6)) after the acute infarct and remained similar to activity on admission (24.8 (1.9) AU/ml (NS) for diabetic and $17.9(6.9) \mathrm{AU} / \mathrm{ml}$ (NS) for non-diabetic patients) and was still significantly higher in diabetic than in non-diabetic patients $(p=0.007)$.

Conclusion-These results show that diabetic patients have higher plasminogen activator inhibitor activity than nondiabetic patients both on admission with acute myocardial infarction and at follow up six to 12 months later. Raised plasminogen activator inhibitor activity may predispose diabetic patients to myocardial infarction and may also impair pharmacological and spontaneous reperfusion after acute myocardial infarction thus contributing to the poor outcome in these subjects.

\section{(Br Heart f 1993;69:228-232)}

Coronary thrombosis plays an important part in most subjects with acute myocardial infarction. ${ }^{12}$ Thrombolytic treatment has been shown to reduce mortality and improve left ventricular function when given for acute myocardial infarction. ${ }^{34}$ Spontaneous thrombolysis also occurs in some patients and may confer similar benefits. ${ }^{2}$ Not all patients treated with a thrombolytic agent successfully reperfuse the thrombosed artery and treatment is further limited by recurrent ischaemia and rethrombosis in $10 \%$ to $25 \%$ of patients. ${ }^{5}$ One factor that could potentially influence the response to thrombolytic treatment and the occurrence of spontaneous thrombolysis is the presence of plasminogen activator inhibitors. Plasminogen activator inhibitor type 1 is the principal inhibitor of thrombolysis under physiological conditions. ${ }^{6}$ Plasminogen activator inhibitor activity has been shown to be high in young survivors of myocardial infarction ${ }^{7}$ and to predispose to reinfarction in these subjects. ${ }^{8}$

Diabetic patients have a high morbidity and mortality from acute myocardial infarction and ischaemic heart disease. ${ }^{910}$ Impaired fibrinolysis and raised plasminogen activator inhibitor activity have been found in diabetic patients without coronary artery disease. ${ }^{112}$ If also present in diabetic patients with myocar- o dial infarction these may be factors contribut- $N$ ing to the poor outcome of these patients. In $\underset{\omega}{N}$ this study we have measured plasminogen 0 activator inhibitor activity in diabetic and $\varrho$ non-diabetic patients on admission with acute myocardial infarction and between six and 12 ? months after myocardial infarction.

\section{Patients and methods}

PATIENT SELECTION

Over a two year period we studied 128 patients admitted with acute myocardial infarction to the Whittington hospital. This represents $60 \%$ of all admissions with acute ? myocardial infarction over this period; patients were excluded from the study if an initial blood sample was not taken before thrombolytic treatment was given, if they presented more than 24 hours after the start 
of chest pain, if cardiopulmonary resuscitation was performed on admission, or if myocardial infarction was not confirmed according to World Health Organisation criteria. ${ }^{13}$

There were 38 diabetic patients of whom 29 were previously diagnosed as having diabetes with a median duration of five years (range six months to 25 years), and nine were newly diagnosed on the basis of admission hyperglycaemia (plasma glucose $\geqslant 11.0$ $\mathrm{mmol} / \mathrm{l}$ ) and raised glycated haemoglobin concentrations. ${ }^{14}$ Of the known diabetic patient 10 were treated by diet alone, 11 were treated with oral hypoglycaemic agents, and eight (two of whom were ketosis prone were treated with insulin. There were 90 non-diabetic patients of whom 12 had admission hyperglycaemia and glycated haemoglobin concentrations within the normal range. Previous work from this unit has shown that over $90 \%$ of patients with hyperglycaemia and normal glycated haemoglobin concentrations on admission with acute myocardial infarction had normal glucose tolerance three months after acute myocardial infarction. ${ }^{14}$

All the patients were admitted within 24 hours of the start of chest pain and myocardial infarction was confirmed according to World Health Organisation criteria. ${ }^{13}$ On admission to hospital and before thrombolytic treatment was given venous blood samples were collected from an antecubital vein with a $21 \mathrm{G}$ needle without venous stasis for estimation of plasminogen activator inhibitor activity and antigen, plasma glucose, glycated haemoglobin, and creatine kinase MB isoenzyme concentrations. Plasma insulin was also measured in the first 38 patients ( 27 non-diabetic and 11 diabetic) included in the study. Repeat creatine kinase MB estimates were performed every six hours for the first 48 hours and then every 12 hours for the next 24 hours. The blood samples for plasminogen activator inhibitor activity and antigen were collected into tubes containing sodium citrate (nine parts of blood were mixed with one part of $3.8 \%$ sodium citrate), centrifuged for 15 minutes at $3000 \mathrm{~g}$ and $4^{\circ} \mathrm{C}$, and the plasma stored at $-70^{\circ} \mathrm{C}$ until analysed.

Between six and 12 months after the original infarction, 40 men were invited to attend for follow up and 18 (45\%) (12 non-diabetic and six diabetic) attended. Fifty patients were not invited to attend because the interval from the original infarction was less than six months in 28,16 patients died either in hospital or after discharge, and six were elderly (>70 years). Blood samples were drawn between 0830 and 0930 after the patients had rested for 10 minutes and had fasted for 12 hours.

The control group consisted of 35 men with no clinical or electrocardiographic evidence of heart disease or hypertension. The 15 non-insulin dependent diabetic patients were randomly selected from the diabetic outpatients clinic over a four week period and the 20 non-diabetic patients were randomly selected from routine admissions for minor surgical procedures recruited over one month. The blood samples were taken before any other intervention. Mean age was 60.9 in the diabetic and 61.4 in the non-diabetic patients.

The study received ethics committee approval and the patients gave informed consent.

ASSAYS

Plasma glucose was measured by a glucose oxidase method (Beckman, Brea, California USA). Glycated haemoglobin was measured by agar gel electrophoresis (Corning Medical, Halstead, UK). Plasminogen activator inhibitor activity was measured by a chromogenic assay (Kabi Diagnostica, Sweden). The interassay coefficient of variation (CV) was $8 \%$ and the intra assay $C V$ was $4.5 \%$. Plasminogen activator inhibitor antigen was measured by an enzyme linked immunosorbent assay (Biopool AB, Sweden). The interassay $\mathrm{CV}$ was $\mathbf{7 . 5 \%}$ and the intra assay $\mathrm{CV}$ was $4.5 \%$. Insulin was measured by radioimmunoassay (Novo Research Institute, Denmark) and creatine kinase $\mathrm{MB}$ by an immunological method (Boehringer Mannheim Diagnostica, France). Serial estimates of creatine kinase MB were used to calculate cumulative creatine kinase $\mathrm{MB}$ isoenzyme release with a modification of the method of Sobel et $a l^{15}$ according to the equation:

Enzyme released $(I U / l)=E(T)+k d \int_{0}^{t} E(t) d t$ Where $\mathrm{E}(\mathrm{T})=$ enzyme concentration at the time of the last available sample $E(t)=$ enzyme concentration at time $t$ after the onset of symptoms, $\mathrm{kd}=$ dissociation constant $=$ $0.095 \mathrm{IU} / \mathrm{h}$

\section{STATISTICAL ANALYSIS}

Results are expressed as mean (SD) for normally distributed data and median and range for skewed data. Differences between groups were tested with unpaired Student's t tests for normally distributed data and Mann-Whitney $\mathrm{U}$ tests for skewed data. Relations between groups were assessed with Pearson's correlation for normally distributed data and Spearman rank correlation for skewed data.

\section{Results}

Table 1 shows the various measurements in the patients studied at admission with acute myocardial infarction. As expected plasma glucose, glycated haemoglobin, and insulin concentrations were significantly higher in diabetic patients than in non-diabetic patients. Infarct size as measured by cumulative creatine kinase $M B$ isoenzyme release (in 75 non-diabetic and 29 diabetic patients) did not differ significantly between the two groups. It was not possible to calculate cumulative creatine kinase $\mathrm{MB}$ isoenzyme release in the remaining $24(19 \%)$ as insufficient samples were taken in 17 and seven died within 48 hours of entering the study.

Ninety six (69 non-diabetic and 27 diabetic) patients received thrombolytic treatment. 
Table 1 Characteristics of diabetic and non-diabetic patients on admission with acute myocardial infarction

\begin{tabular}{|c|c|c|c|}
\hline Variable & $\begin{array}{l}\text { Diabetic } \\
(n=38)\end{array}$ & $\begin{array}{l}\text { Non-diabetic } \\
(n=90)\end{array}$ & p Value \\
\hline Age $(y r)$ & $64 \cdot 6(8 \cdot 8)$ & $65 \cdot 5(12 \cdot 0)$ & NS \\
\hline $\operatorname{Sex}(M: F)$ & 28:10 & $62: 28$ & NS \\
\hline Anterior infarction & $55 \cdot 3 \%$ & $45 \cdot 6 \%$ & NS \\
\hline Inferior infarction & $28 \cdot 9 \%$ & $42 \cdot 2 \%$ & \\
\hline Time from start of chest pain (h) & $6(2 \cdot 0-24)$ & $5(0.5-24)$ & NS \\
\hline Plasma glucose on admission $(\mathrm{mmol} / \mathrm{l})$ & $17 \cdot 4(8.9)$ & $8 \cdot 4(2 \cdot 3)$ & 0.0001 \\
\hline Glycated haemoglobin (\%) & $10 \cdot 2(2 \cdot 1)$ & $7 \cdot 1(0.7)$ & 0.0001 \\
\hline Plasma insulin $(\mathrm{mU} / \mathrm{ml})$ on admission & $\begin{array}{l}\quad 6 \cdot 4(10 \cdot 5-55 \cdot 2) \\
(\mathrm{n}=11)\end{array}$ & $\begin{array}{l}13.7(5 \cdot 7-36 \cdot 7) \\
(\mathrm{n}=27)\end{array}$ & 0.003 \\
\hline CK-CR (IU/l) & $\begin{array}{l}205(98-572) \\
(n=29)\end{array}$ & $\begin{array}{l}237(46-655) \\
(n=75)\end{array}$ & NS \\
\hline $\begin{array}{l}\text { PAI-1 activity (AU/ml) } \\
\text { PAI-1 antigen }(\mathrm{ng} / \mathrm{ml})\end{array}$ & $\begin{array}{l}24 \cdot 7(6 \cdot 8) \\
64 \cdot 2(13 \cdot 1-328 \cdot 8)\end{array}$ & $\begin{array}{l}18.5(6.8) \\
38.5(10.9-173.7)\end{array}$ & $\begin{array}{l}0.0001 \\
0.0008\end{array}$ \\
\hline
\end{tabular}

Values are mean (SD) for normally distributed data and median and range for skewed data. CK-CR, cumulative creatine kinase MB isoenzyme release; PAI-1, plasminogen activator inhibitor type 1;AU, arbitrary units.

During the period of this study, the hospital was participating in a randomised study of thrombolytic treatment in acute myocardial infarction (the third international study of infarct survival (ISIS 3)) and consequently the thrombolytic agents used were streptokinase in 62 (44 non-diabetic and 18 diabetic), anistreplase in 12 (seven non-diabetic and five diabetic), and recombinant tissue plasminogen activator in 22 (18 non-diabetic and four diabetic) patients.

Table 2 shows plasminogen activator inhibitor activity and plasminogen activator inhibitor antigen concentrations in diabetic and non-diabetic controls and in the patients admitted with acute myocardial infarction. Both the diabetic and non-diabetic patients admitted with acute myocardial infarction had significantly higher plasminogen activator inhibitor activity and antigen concentrations than their respective control groups. Plasminogen activator inhibitor activity was also significantly higher in the diabetic control group compared with the non-diabetic control group. In the patients admitted with acute myocardial infarction, both plasminogen activator inhibitor activity and plasminogen activator inhibitor antigen concentration were significantly higher in diabetic compared with non-diabetic patients. There was a positive correlation between activity and antigen of $0.56(p=0.0001)$. There were no significant differences in plasminogen activator inhibitor activities between non-diabetic patients with or without admission hyperglycaemia or between newly diagnosed and previously known diabetic patients (table 3 ). Plasminogen activator inhibitor antigen concentrations but not inhibitor activities were significantly higher in patients with admission hyperglycaemia than in normoglycaemic patients (table 3 ).

In all patients combined there was a positive correlation between plasminogen activator inhibitor activity and admission plasma glucose, glycated haemoglobin, admission plasma insulin (38 patients), and Killip grade of heart failure on admission and on discharge (table 4). Plasminogen activator inhibitor antigen also correlated positively with admission plasma glucose, glycated haemoglobin and Killip grade of heart failure on discharge (table 4). Neither plasminogen activator inhibitor activity nor antigen correlated with infarct size as estimated by cumulative creatine kinase $\mathrm{MB}$ isoenzyme release $(\mathrm{n}=104)\left(r_{\mathrm{s}}=-0.08 ; \mathrm{NS}\right.$, and $\left(r_{\mathrm{s}}=\right.$ $-0 \cdot 16$; NS). When the groups were analysed separately only the correlation between plasminogen activator inhibitor activity and plasma insulin remained.

In 18 of the patients (12 non-diabetic and six diabetic) plasminogen activator inhibitor activity was measured between six and 12 months after the acute infarct and activities were again higher in diabetic compared with non-diabetic patients (table 5). Comparison of changes within individual patients between admission and follow up showed no significant difference.

\section{Discussion}

Plasminogen activator inhibitor activity has been found to be increased in thrombotic disorders including deep venous thrombosis, ${ }^{16}$

Table 2 Plasminogen activator inhibitor type 1 (PAI-1) activity and PAI-1 antigen concentrations in diabetic and nondiabetic patients and controls

\begin{tabular}{|c|c|c|c|c|c|c|}
\hline & \multicolumn{3}{|l|}{ Diabetic } & \multicolumn{3}{|l|}{ Non-diabetic } \\
\hline & $\begin{array}{l}\text { Patients } \\
(n=38)\end{array}$ & $\begin{array}{l}\text { Controls } \\
(n=15)\end{array}$ & p Value & $\begin{array}{l}\text { Patients } \\
(n=90)\end{array}$ & $\begin{array}{l}\text { Controls } \\
(n=20)\end{array}$ & p Value \\
\hline $\begin{array}{l}\text { PAI-1 antigen (AU/ml) } \\
\text { PAI-1 antigen ( } \mathrm{ng} / \mathrm{ml})\end{array}$ & $\begin{array}{l}24 \cdot 7(6 \cdot 8) \\
64 \cdot 2(13 \cdot 1-328 \cdot 8)\end{array}$ & $\begin{array}{l}18 \cdot 7(5 \cdot 6) \\
24 \cdot 3(9 \cdot 8-41 \cdot 1)\end{array}$ & $\begin{array}{l}0.002 \\
0.0001\end{array}$ & $\begin{array}{l}18 \cdot 5(6 \cdot 8) \\
38 \cdot 5(10 \cdot 9-173 \cdot 7)\end{array}$ & $\begin{array}{l}12 \cdot 0(3 \cdot 8) \\
19 \cdot 9(4 \cdot 5-52 \cdot 7)\end{array}$ & $\begin{array}{l}0.0001 \\
0.0001\end{array}$ \\
\hline
\end{tabular}

Table 3 Plasminogen activator inhibitor type 1 (PAI-1) activity and antigen concentrations on admission with acute myocardial infarction in non-diabetic, hyperglycaemic, and diabetic (previously known and newly diagnosed) patients

\begin{tabular}{|c|c|c|c|c|}
\hline & \multicolumn{2}{|l|}{ Non-diabetic } & \multicolumn{2}{|l|}{ Diabetic } \\
\hline & $\begin{array}{l}\text { Normoglycaemic } \\
(n=7)\end{array}$ & $\begin{array}{l}\text { Hyperglycaemia } \\
\text { on admission } \\
(n=12)\end{array}$ & $\begin{array}{l}\text { Known diabetic } \\
(n=29)\end{array}$ & $\begin{array}{l}\text { Newuly diagnosed } \\
\text { diabetic } \\
(n=9)\end{array}$ \\
\hline $\begin{array}{l}\text { PAI-1 activity (AU/ml) } \\
\text { PAI-1 antigen ( } \mathrm{ng} / \mathrm{ml})\end{array}$ & $\begin{array}{l}18.3(6 \cdot 4) \\
36.9(10 \cdot 9-118 \cdot 1)\end{array}$ & $\begin{array}{l}19 \cdot 2(9 \cdot 3) \\
54 \cdot 8(28 \cdot 9-173 \cdot 7)^{\star}\end{array}$ & $\begin{array}{l}24 \cdot 2(6 \cdot 3) \\
60 \cdot 8(19 \cdot 0-328 \cdot 8)\end{array}$ & $\begin{array}{l}26.3(8 \cdot 3) \\
73.9(13 \cdot 1-220 \cdot 6)\end{array}$ \\
\hline
\end{tabular}

Footnotes as For table 1

${ }^{\star} \mathrm{p}=0.04$ compared with normoglycaemic subjects 
Table 4 Correlation coefficients between both plasminogen activator inhibitor type 1 (PAI-1) activity and antigen and variables of diabetic control and indicators of infarct size in all patients combined

\begin{tabular}{llll}
\hline & $\begin{array}{l}\text { PAI-1 activity } \\
r_{s}(p \text { value })\end{array}$ & $\begin{array}{l}\text { PAI-1 antigen } \\
r_{s}(p \text { value }\end{array}$ & $\begin{array}{l}\text { Plasma glucose on admission } \\
r_{s}(p \text { value })\end{array}$ \\
\hline PAI-1 antigen & $0.51(0.0001)$ & & \\
Plasma glucose on admission & $0.32(0.0001)$ & $0.26(0.002)$ & \\
Glycated haemoglobin & $0.32(0.0001)$ & $0.23(0.007)$ & $0.69(0.0001)$ \\
Plasma insulin on admission & $0.48(0.001)$ & $0.26(0.06)$ & $0.43(0.004)$ \\
CK-CR & $\mathrm{NS}$ & $\mathrm{NS}$ & $\mathrm{NS}$ \\
Killip grade (on admission) & $0.27(0.001)$ & $\mathrm{NS}(0.02)$ \\
Killip grade (on discharge) & $0.22(0.006)$ & $0.19(0.02)$ & $0.28(0.001)$ \\
\hline
\end{tabular}

Footnotes as for table 1 .

unstable angina, ${ }^{17}$ and acute myocardial infarction. ${ }^{18}$ In this study we found that plasminogen activator inhibitor concentrations were raised in patients admitted with acute myocardial infarction, and that both activity and antigen concentration were higher in diabetic compared with non-diabetic patients both on admission with acute myocardial infarction and at follow up six to 12 months later.

Diabetic patients have a high mortality from acute myocardial infarction, with heart failure and cardiogenic shock, the most common causes of death. The reasons for this excess mortality are unknown. We and others have previously shown that diabetic patients do not seem to have larger infarcts than nondiabetic patients. ${ }^{919}$ One possibility is that impaired fibrinolytic activity in diabetic patients predisposes them to coronary thrombosis, impairs their response to spontaneous and pharmacological reperfusion, and predisposes to rethrombosis after successful reperfusion.

The role of plasminogen activator inhibitor in determining the occurrence of spontaneous reperfusion and the outcome from thrombolytic treatment or both is still unclear. In the Thrombolysis and Myocardial Infarction (TAMI) study lower plasminogen activator inhibitor antigen but not plasminogen activator inhibitor activities correlated with greater patency at the 90 minute angiogram. ${ }^{20}$ Barbash et al found significantly higher baseline plasminogen activator inhibitor activity in patients with non-patent infarct related arteries three days after giving recombinant tissue plasminogen activator. ${ }^{21}$ Both studies, therefore, have suggested a relation between high concentrations of plasminogen activator inhibitor and a decreased likelihood of a patent infarct related artery.

Concentrations of pharmacological recombinant tissue plasminogen activator range from one to three $\mu \mathrm{g}$ and so it is likely that in the average patient plasminogen activator inhibitor activity is overwhelmed by an excess

Table 5 Plasminogen activator inhibitor type 1 (PAI-1) activity (AU/ml) in diabetic and non-diabetic patients on admission with acute myocardial infarction and at six to 12 months later

\begin{tabular}{llll}
\hline & $\begin{array}{l}\text { Diabetic } \\
(n=6)\end{array}$ & $\begin{array}{l}\text { Non-diabetic } \\
(n=12)\end{array}$ & p Value \\
\hline Acute infarct & $21.6(4.9)$ & $15.5(5.7)$ & 0.04 \\
Follow up & $24.8(1.9)$ & $17.9(6.9)$ & 0.0007 \\
\hline
\end{tabular}

Footnotes as for table 1 . of thrombolytic agent with standard treatment protocols. However, in patients with very high baseline plasminogen activator inhibitor concentrations neutralisation of a variable but significant portion of the administered drug may occur and reduce the likelihood of reperfusion. Also the inhibitory effect of plasminogen activator inhibitor may be more important after infusion of thrombolytic agents has finished and may predispose to reocclusion and reinfarction. Lucore et al found that infused tissue plasminogen activator initially saturates plasminogen activator inhibitor and circulates as free tissue plasminogen activator and in a complex with protease inhibitors. ${ }^{22}$ Their findings also suggested that raised plasminogen activator inhibitor activity associated with myocardial infarction reduced the activity of substantial amounts of residual plasma tissue plasminogen activator after the infusion had ended. As yet there are no studies looking at the effect of plasminogen activator inhibitor on thrombolytic treatment with streptokinase or anistreplase. As both these agents, like tissue plasminogen activator inhibitor, exert their thrombolytic effect by generation of plasmin from its inactive precursor, plasminogen. It is possible that plasminogen activator inhibitor may have similar effects on reperfusion and reocclusion in patients treated with these agents. It is possible, therefore that the higher plasminogen activator inhibitor concentrations in diabetic patients with acute infarction may reduce their likelihood of initial reperfusion and increase their risk of rethrombosis and reinfarction and thus contribute to their poor outcome.

The cause of the raised plasminogen activator inhibitor concentration in diabetic patients cannot be determined from this study. The correlations between plasminogen activator inhibitor and both admission plasma glucose and glycated haemoglobin may simply reflect the fact that the diabetic patients had higher plasma glucose and glycated haemoglobin concentrations and also had higher plasminogen activator inhibitor concentrations rather than a cause and effect relation. Plasminogen activator inhibitor activities also correlated significantly with plasma insulin in these patients. Juhan-Vague et al found a relation between plasma insulin and plasminogen activator inhibitor in different groups including obese subjects, noninsulin dependent diabetic patients, and angina pectoris. ${ }^{2324}$ Insulin has also been shown to stimulate hepatic production of 
plasminogen activator inhibitor. ${ }^{25}$ The finding that the relation between plasminogen activator inhibitor and plasma insulin persists in the setting of acute myocardial infarction suggests that insulin may be an important regulator of fibrinolysis. However, our own findings that plasminogen activator inhibitor activity in non-insulin dependent diabetic patients correlates better with concentrations of des 31,32 proinsulin (32, 33 split proinsulin) than with those of insulin itself $^{26}$ mean that such conclusions require further investigation with specific assays for insulin and proinsulin like molecules. ${ }^{27} 28$

In a small number of patients we found that plasminogen activator inhibitor activity remained higher in diabetic patients compared with non-diabetic patients at follow up between six and 12 months after the acute event. Plasminogen activator inhibitor activity was also higher in the diabetic controls compared with the non-diabetic controls. This indicates that diabetic patients without clinical evidence of heart disease also have raised plasminogen activator inhibitor activity and confirms previous findings. ${ }^{1112}$ Whether the increased plasminogen activator inhibitor in the patients with acute infarction is a cause or a consequence of the acute infarction is not clear from this study. It has been suggested that plasminogen activator inhibitor is an acute phase reactant but this effect would be unlikely to persist six months after the acute infarction. Also others have shown that raised plasminogen activator inhibitor activities are independent of acute ischaemic events ${ }^{29}$ and so are unlikely to be acute phase reactants. Moreover, the circadian variation found in normal people persists in acute infarction. ${ }^{29}$ It should be noted that all samples at six to 12 months were morning samples, unlike those taken on admission with acute infarction and this may affect the comparability of these values. In view of the effects of exercise and posture on fibrinolytic activity, ${ }^{30}$ a 10 minute rest period before samples were taken in this study may well be insufficient to control for any effect of exercise on plasminogen activator inhibitor activity. All the samples, however, were taken in the morning and none of the subjects had engaged in any form of strenuous exercise immediately before the study.

In conclusion, we have shown that diabetic patients admitted with acute myocardial infarction have reduced fibrinolytic activity as shown by raised plasminogen activator inhibitor activities compared with non-diabetic patients and controls. The role of plasminogen activator inhibitor in determining the outcome from spontaneous and or pharmacological reperfusion or the occurrence of reocclusion is still not clear and requires further study. This study was supported by a locally organised research
grant from the North East Thames Regional Health grant from
Authority.

1 Davies M, Woolf N, Robertson WB. Pathology of acute myocardial infarction with sive coronary thrombi. Br Heart $\mathcal{f}$ 1976;38:659-64.
2 De Wood M A, Spores J, Notske R, et al. Prevalence of total coronary occlusion during the early hours of transmural myocardial infarction. $N$ Engl $\mathcal{f}$ Med 1980;303: 897-902.

3 ISIS-2 Collaborative Group. Randomised trial of intravenous streptokinase, oral aspirin or both or neither among 17187 cases of suspected acute myocardial infarction, ISIS-2. Lancet 1988;ii:349-60.

4 White HD, Norris RM, Brown MA, et al. Effect of intravenous streptokinase on left ventricular function and venous streptokinase on left ventricular function and
early survival after acute myocardial infarction. $N$ Engl $\mathcal{F}$

5 TIMI Study Group. The Thrombolysis in Myocardial Infarction trial: phase 1 findings. $N$ Engl $\mathcal{f}$ Med 1985; 312:932-6.

6 Loskutoff DJ, Sawdey M, Mimuro J. Type 1 plasminogen activator inhibitor. In: Coller BS, ed. Progress in hemostasis and thrombosis. Vol 9. Philadelphia: WB Saunders 1989: 87-115.

7 Hamsten A, Wiman B, DE Faire U, Blomback $M$ Increased plasma levels of a rapid inhibitor of tissue plasminogen activator in young survivors of myocardial plasminogen activator in young survivors of

8 Hamsten A, Walldius G, Szamosi A, et al. Plasminogen activator inhibitor in plasma: risk factor for recurrent myocardial infarction. Lancet 1987;1:3-8.

9 Yudkin JS, Oswald GA. Hyperglycaemia, diabetes and myocardial infarction. Diabetic Med 1987;4:13-8.

10 Gwilt DJ. Why do diabetic patients die after myocardial infarction. Practical Diabetes 1984;1:36-9.

11 Auwerx J, Bouillon R, Collen D, Geboers J. Tissue-type plasminogen activator antigen and plasminogen activator inhibitor in diabetes mellitus. Arteriosclerosis $1988 ; 8$. 68-72.

12 Juhan-Vague I, Roul C, Alessi MC, Ardissone JP, Helm $M$, Vague $P$. Increased plasminogen activator inhibitor in non insulin dependent diabetic patients-relationship in non insulin dependent diabetic patients-relationsh
with plasma insulin. Thromb Haemost 1989;61:370-3.

13 World Health Organisation regional office for Europe. Public health in Europe 5. Myocardial infarction community registers. Copenhagen: WHO 1976. (Annexe 1.)

14 Oswald GA, Yudkin JS. Hyperglycaemia following acute myocardial infarction: the contribution of undiagnosed diabetes. Diabetic Med 1987;4:68-70.

15 Sobel BE, Bresnahan GF, Shell WE, Yoder RD Estimation of infarct size in man and its relation to prognosis. Circulation 1972;46:640-8.

16 Wiman B, Lljungberg B, Chmielewska J, Urden G, Blomback M, Johnsson $H$. The role of the fibrinolytic system in deep vein thrombosis. 7 Lab Clin Med 1985; 105:265-70.

17 Zalewski A, Shi Y, Nardone D, et al. Evidence for reduced fibrinolytic activity in unstable angina at rest. Circulation 1991;83:1685-91

18 Almer L, Ohlin $\mathrm{H}$. Elevated levels of the rapid inhibitor of plasminogen activator (t-PAI) in acute myocardial infarction. Thromb Res 1987;47:335-9.

19 Gwilt DJ, Petri M, Lewis PW, Natrass M, Pentecost BL. Myocardial infarct size in diabetic patients. Br Heart $\mathcal{f}$ 1985;54:466-72.

20 Sane DC, Stump DC, Topol EJ, et al. Correlation between baseline plasminogen activator inhibitor levels and clinical outcome during therapy with tissue plasminogen activator for acute myocardial infarction. minogen activator for acute
Thromb Haemost 1991;65:275-9.

21 Barbash GI, Hod H, Roth A, et al. Correlation of baseline plasminogen activator inhibitor with patency of the infarct artery after thrombolytic therapy in acute myocardial infarction. Am $\mathcal{F}$ Cardiol 1989;64:1231-5.

22 Lucore CL, Sobel BE. Interactions of tissue type plasminogen activator with plasma inhibitors and their pharmacological implications. Circulation 1988;77:660-9.

23 Vague P, Juhan-Vague I, Aillaud MF, et al. Correlation between blood fibrinolytic activity, plasminogen activator inhibitor level, plasma insulin level, and relative body weight in normal and obese subjects. Metabolism 1986;35:250-3.

24 Juhan-Vague I, Alessi MC, Joly P, et al. Plasma plasminogen activator inhibitor -1 in angina pectoris. gen activator inhibitor
Arteriosclerosis 1989;9:362-7.

25 Alessi MC, Juhan-Vague I, Kooistra T, Declerck PJ, Collen D. Insulin stimulates the synthesis of plasminogen activator inhibitor type 1 by the human hepatom cell line HepG2. Thromb Haemost 1988;60:491-4.

26 Nagi DK, Hendra TJ, Ryle AJ, et al. The relationships of concentrations of insulin, intact proinsulin and 32-33 split proinsulin with cardiovascular risk factors in type 2 non insulin dependent) diabetic subjects. Diabetologia 1990;33:532-7.

27 Temple RC, Carrington CA, Luzio SD, et al. Insulin deficiency in non insulin dependent diabetes. Lancet 1989 i: $293-5$.

28 Sobey WJ, Beer SF, Carrington CA, et al. Sensitive and specific two site immunoradiometric assays for human insulin, proinsulin, 65-66 split and 23-33 split proinsulins. Biochem 7 1989;260:535-41.

29 Huber K, Rosc D, Resch I, et al. Circadian fluctuations of plasminogen activator inhibitor and tissue plasminogen plasminogen activator inhibitor and tissue plasminogen
activator levels in plasma of patients with unstable coroactivator levels in plasma of patients with unstable coronary artery disease and acute
Thromb Haemost 1988;60:372-6.

30 Wiman B, Mellbring G, Ranby M. Plasminogen activator release during venous stasis and exercise as determined by a new specific assay. Clin Chim Acta 1983;127 279-88. 